\title{
EL EJERCICIO DE CONTROL DE CONSTITUCIONALIDAD POR LOS JUECES PERUANOS
}

\author{
IVÁN SEQUEIROS VARGAS*
}

\begin{abstract}
Resumen
El juez tiene el poder y debe inaplicar una norma legal contraria a la Constitución a fin de contribuir con la preservación de la supremacía constitucional, como referente del buen gobierno y desarrollo del Estado; no obstante, en algo más de veintisiete años el Poder Judicial en poquísimas ocasiones declaró inaplicable una norma legal, lo que demuestra la renuencia en el ejercicio de esta atribución. El control constitucional constituye una tarea compleja y es evitada por los jueces en razón de las implicancias de toda naturaleza que pueden derivarse de su decisión, siendo además que el presupuesto señalado por el Tribunal Constitucional relativo a la "evidente incompatibilidad" sea probablemente uno de los factores que influyen en la escasa ejecutoria de control, pues ninguna norma resulta evidentemente no constitucional o viceversa a la vista del buen evaluador, constituyéndose en un concepto incierto, inviable y subjetivo que no delimita ni sirve de referencia para que el juez efectúe el control que le atribuye la Constitución y la ley.
\end{abstract}

Palabras clave: Control de constitucionalidad - Control difuso.

\begin{abstract}
Judges have the authority and must not apply a statutory law contrary to the Constitution in order to contribute to preserve constitutional supremacy, as an example of the good governance and government development; notwithstanding, in over twenty seven years, the Judiciary, on very few occasions, has declared a statutory law not applicable, which proves the reluctance to exercise this authority. Constitutional control is a complex task and judges avoid it due to all different implications that could result from their decisions. Additionally, the assumption indicated by the Constitutional Court regarding "clear incompatibility" would probably be one of the reasons influencing limited control enforcement, because no regulation turns out to be clearly non constitutional or vice versa at the sight of a good assessor. It results in an uncertain, unfeasible, and subjective concept, which does not limit or serve as reference for a judge to perform the control conferred on him by the Constitution and the Law.
\end{abstract}

Key words: Constitutionality Control - Diffused control.

Sumario

El ejercicio del control de constitucionalidad por los jueces peruanos.

\footnotetext{
* Juez Superior Titular de la Corte Superior de Justicia de Lima - Poder Judicial de Perú. Profesor de la Universidad Particular San Martín de Porres y la Academia de la Magistratura.
} 
Un Estado con vigencia plena de la teoría de supremacía constitucional sería un Estado ideal, no tendría problemas constitucionales, judiciales y sociales, sin embargo, aún cuando dicha teoría es universalmente aceptada y unánimemente respaldada, su realización vivida resulta deficiente, razón por la que los mecanismos de control de constitucionalidad adquieren singular importancia ya que contribuyen directamente en el soporte efectivo de la mencionada teoría, de manera tal que en la medida que los controles de constitucionalidad funcionen, los estados serán más viables, probablemente mejor desarrollados y la vigencia de los derechos tiene mayor equilibrio. No es nuestro propósito evaluar la supremacía constitucional ni los mecanismos de control de constitucionalidad, sería mucha pretensión, sino únicamente referirnos al ejercicio disminuido de esta atribución por parte de los jueces peruanos.

Los sistemas de control de constitucionalidad, pueden abarcarse desde dos perspectivas diferentes, pero coherentes y complementarias, una vertiente política ${ }^{1}$ (desarrollado por entidades políticas y sobre argumentos esencialmente políticos) y otra jurídica, (en manos de órganos jurídicos fundamentalmente y sobre razones jurídicas esencialmente), igualmente importantes las dos, inescindibles, necesarias, complejas, lo que nos determina, en este caso, referirnos al ejercicio de esta potestad por parte de la función judicial del Estado, atribución al parecer venida a menos por factores diversos.

Kelsen cuando desarrolla la teoría para justificar la existencia de las Cortes Constitucionales $^{2}$, señala que los jueces resultan ineficaces en el control de constitucionalidad ${ }^{3}$, ya sea por excesiva carga procesal, por falta de interés en esta atribución, o simplemente por desidia e inclusive por incapacidad y falta de tradición. Ha transcurrido casi un siglo y el control de constitucionalidad por parte de los jueces no ha cambiado sustancialmente y es probable que se haya estancado o tal vez retrocedido en vista del desarrollo que han tenido algunas cortes constitucionales, como en nuestro caso, aspectos que evaluaremos dentro de las limitaciones de espacio que circunscriben artículos en una revista de esta naturaleza. En el sistema anglosajón, donde no han tenido cabida las cortes constitucionales, la función judicial del Estado sigue ejerciendo hegemonía en el control de constitucionalidad.

Si preguntamos cuántas veces en el Perú, los jueces han inaplicado una norma legal por inconstitucional, la respuesta es obvia ${ }^{4}$, pues en algo más de veintisiete años el Poder Judicial en poquísimas ocasiones declaró inaplicable una norma legal ${ }^{5}$, lo que demuestra de manera palmaria la renuencia al ejercicio de esta atribución, salvo que admitan que todas las demás normas resultan constitucionales, lo que resulta cuando menos discutible, más aún 
si tenemos en cuenta que el Tribunal Constitucional (en adelante TC), ha declarado muchas normas inconstitucionales.

Evidentemente no es cuestión cuantitativa la materia, a mayor número de inaplicaciones normativas el ejercicio de la atribución es bueno y viceversa, no discurrimos por ese facilismo, aun cuando esta perspectiva, en un país como el nuestro, donde los que tienen potestad normativa y detentan poderes dentro de la administración pública, tienen la tendencia de invadir fueros constitucionales directa o subrepticiamente y peor aún si nos damos cuenta que el desarrollo de los derechos fundamentales ha puesto en tela de juicio muchas normas legales de carácter sustantivo y procesal que en ocasiones resultan abiertamente no constitucionales ${ }^{6}$. Pretendemos mas bien determinar lo sustancial de la atribución, las razones de tan escasa ejecutoria y de manera irreverente sugerir cuáles son las perspectivas en esta materia trascendental para la función judicial del Estado.

El artículo $138^{\circ}$ de la vigente Carta Fundamental reitera a los jueces que deben aplicar la Constitución si una norma es incompatible con ella, es reiteración de lo que establecía el texto constitucional de 1979 y encontramos como antecedente constitucional remoto de la supremacía constitucional el artículo $10^{\circ}$ de la Constitución de $1856^{7}$. Es verdad que esta norma ya no se repite hasta el Código Civil de $1936^{8}$, debido a que la Constitución de 1870 (la de mayor duración), elimina la primera parte del artículo citado, la de 1920 no reitera el texto de 1856, pero además se incluye en la Ley Orgánica del Poder Judicial $N^{\circ} 14605$, cuyo artículo $8^{\circ}$ reitera el concepto.

La Constitución de 1979, con claridad semántica, pero esencialmente con conocimiento trascendental de la materia, después de un debate esclarecedor incluye el control de constitucionalidad judicial a través de la inaplicación normativa ${ }^{9}$. El texto constitucional vigente de 1993 reitera el concepto y adicionalmente la Ley Orgánica del Poder Judicial (en adelante LOPJ) (artículo $14^{\circ}$ ), que siguiendo la noción de no reiterar lo que dice la Constitución la desarrolla, como ocurre con otros artículos, precisando el procedimiento y esencialmente protegiendo el propósito de dicha función de control y el novísimo Código Procesal Constitucional también reitera el concepto a través de su artículo VI del Título Preliminar.

Teniendo en cuenta, la teoría de la dispersión del poder ${ }^{10}$, el propósito fundamental que sustenta el ejercicio equilibrado del poder político, la Supremacía de la Constitución y las normas legales descritas, resulta incuestionable que el juez, tiene el poder y debe inaplicar una norma legal contraria a la Consti- 
Iván Sequeiros Vargas - Ejercicio de control de constitucionalidad

por los jueces peruanos

tución, atribución que más allá de la trascendencia jurídica involucra evidentemente un ejercicio de poder real, que contribuye en el control de los excesos de quien detenta el poder y sus decisiones (contenidas en normas legales) resulten conformes con la Constitución, pues finalmente lo que se busca es que también los jueces contribuyan en la preservación de la supremacía constitucional, como referente sustancial del buen gobierno y desarrollo del Estado.

Evidentemente este control implica una tarea compleja, ya que no se refiere a una mera comparación entre lo que dice la norma y lo que fluye de la Constitución, sino que necesariamente requiere de una exhaustiva y cuidadosa evaluación de los propósitos constitucionales con referencia de toda la teoría de la interpretación constitucional y legal y adicionalmente se debe tener como referencia esencial la solución del caso especifico y no perder de vista los efectos de la resolución, ya no solo circunscrito al caso específico, sino a la sociedad en su conjunto, de ahí que uno de los factores que influye en la escasísima ejecutoria de control difuso, resulta explicada. Los jueces evitan el control, en razón de las implicancias de toda naturaleza que pueden derivarse de su decisión, por tanto, requiere ponderación, mesura, extremo cuidado, información suficiente, tanto doctrinaria, constitucional, como legal y ejecutoria referida al caso, sin dejar de lado las consecuencias de su decisión.

Al puntualizar estos criterios, tengo la sensación que estamos únicamente destacando la labor de los jueces en todas sus decisiones, significa esto que al resolver cualquier asunto sometido a su competencia tienen que hacerlo con todos estos rigores, pero con mayor prestancia y dedicación cuando se trata de un tema de control de constitucionalidad, entonces volvemos a lo que Kelsen señalaba en términos concretos, los jueces no pueden dedicar un tiempo especial para involucrarse en un análisis trascendental de control de constitucionalidad, lo que no justifica su ineficiencia en esta materia, sino que la explica.

Es cierto que el control de constitucionalidad que deben realizar los jueces, tienen determinadas condiciones para su desenvolvimiento, en efecto se exige que la norma en cuestión de constitucionalidad sea fundamental para resolver el caso, pues de otro modo cualquier norma accesoria de aplicación inclusive referencial, podría originar vocación de control y por tanto convertir, eventualmente a un juez, en contralor excesivo de constitucionalidad, con lo que incurre en el mismo o peor defecto de exceso de poder, del que quiere controlar.

Se requiere, por otro lado, que la inconstitucionalidad de la norma sea manifiesta, requerimiento extremadamente subjetivo, que nos obliga a un intenso debate de difícil solución. Los criterios más exigentes dicen que esta inconsti- 
tucionalidad manifiesta debe traer como consecuencia que la norma en cuestión, no tiene interpretación constitucional válida, se sustenta este criterio en la presunción de constitucionalidad con la que nacen todas las normas legales y por su puesto en la supremacía constitucional ${ }^{11}$. Significa que inaplicar una ley, solo será posible si la Constitución dice blanco y la norma dice negro, creo que estos no son los extremos que se pretende, pues resulta más que evidente que las normas legales no pueden tener esa catadura de contravenir abierta y francamente lo que dice la Constitución, por el contrario, muchas normas se "disfrazan" de constitucionalidad y no son "evidentemente" inconstitucionales, que es lo que usualmente origina que su aplicación no solo aparenta resolver el caso dentro de un manto de constitucionalidad, sino que además origina injusticias monstruosas.

Por esa razón es que la evidencia de la inconstitucionalidad, no está referida al lego que discrimine el blanco del negro o el día de la noche, sino que se somete a la capacidad de evaluación del juez, quien con su carga informativa en asuntos jurídicos, su versación doctrinaria, su experiencia, el contexto social, político, económico y en torno del caso específico, descubre aquello que no resulta evidente y plantea la inconveniencia de aplicar la norma en razón de la preferencia constitucional, solo de esa manera cumple razonablemente su rol de juez.

Circunscribir su potestad de control a la mera comparación semántica de la norma y la Constitución o a la simple constatación del texto de ambas normas, no responde a un racional criterio de constitucionalidad o no, sino que siguiendo la teoría de la interpretación normativa y con referencia de la teoría de la interpretación constitucional que en su acepción primaria por ser norma también se somete a las reglas de la interpretación en general, tiene que hacer un esfuerzo hermenéutico y un análisis trascendental, para que la aplicación de la Constitución resulte importante para el caso y resuelva con justicia y equidad.

Estos criterios limitativos, fueron deducidos por el $\mathrm{TC}^{12}$. después que entró en vigencia la Ley Procesal Constitucional, en efecto cita el TC que el "ejercicio [de control de constitucionalidad] no es un acto simple [nadie sostiene lo contrario] y para que el sea válido se requiere de la verificación, en cada caso, de los siguientes presupuestos" [agregado nuestro]:

1. Que en el proceso constitucional, el objeto de la impugnación sea un acto que constituya la inaplicación de una norma considerada inconstitucional (artículo $3^{\circ}$ de la Ley $\mathrm{N}^{\circ} 23506$ ); 
Iván Sequeiros Vargas - Ejercicio de control de constitucionalidad

por los jueces peruanos

2. Que la norma a inaplicarse tenga una relevancia directa, principal e indisoluble con la resolución del caso, es decir, que ella sea relevante en la resolución de la controversia; y,

3. Que la norma a inaplicarse resulte evidentemente incompatible con la Constitución, aun luego de haberse acudido a interpretarla de conformidad con la Constitución, en virtud del principio enunciado en la Segunda Disposición General de la Ley Orgánica del TC ${ }^{13}$.

Sin lugar a ninguna duda, constituyen estas limitaciones una suerte de advertencia, que al parecer pretenden restringir la potestad judicial del control de constitucionalidad, entendemos que este propósito tiene la finalidad de otorgarle estabilidad al sistema normativo, lo que resulta necesario y correcto, sin embargo, al ya restringido ánimo de los jueces de contribuir en el control de constitucionalidad, se incluye anotaciones que virtualmente descartan en la vocación de los jueces la posibilidad de control pero debemos "interpretar" adecuadamente estos conceptos.

¿Están prohibidos los jueces de interpretar la Constitución?, definitivamente no; por el contrario, para aplicar en la solución de los conflictos sometidos a su competencia, tienen facultad plena de interpretar la Constitución, actividad que se advierte en muchas resoluciones judiciales, donde la aplicación de la norma sustantiva no es meramente semántica, por el contrario es producto de una interpretación suficientemente racional, correcta y adecuada, entonces tenemos un primer elemento de referencia que nos permite aseverar que la interpretación constitucional no es asunto exclusivo del TC o del Congreso, los jueces tienen obligación de interpretar y aplicar la Constitución, tan cierto y evidente es este concepto que antes de la vigencia de las Cortes Constitucionales eran los jueces quienes tenían preponderancia en la interpretación constitucional y en el sistema anglosajón, aún prevalece esta forma de decidir lo que significa la Constitución, con carácter definitivo.

¿Cuando resulta "evidentemente incompatible" una norma con la Constitución?, o ¿qué debemos entender en esos términos? es una cuestión que ciertamente origina un debate extremadamente subjetivo, sutil y de contornos imprecisos, porque en ocasiones lo obvio no resulta tan sencillo de entender ${ }^{14}$. En la práctica encontraremos muchas normas "evidentemente incompatibles" a "simple vista" pero analizadas debidamente no tienen esa condición, lo que origina que ese requisito para inaplicar una ley resulta cuando menos cuestionable, sino impracticable y por cierto carente de trascendencia para resolver un conflicto normativo. La teoría de las traslaciones y mutaciones constitucionales en ocasiones nos remiten a la necesidad de interpretar la Constitución 
en función de determinada ley que por su trascendencia llena o reemplaza algún vacío o deficiencia de la Constitución, de ahí que no toda norma de apariencia constitucional lo es y viceversa.

Muchas normas a "ojo de buen cubero", resultan por su textura, por razones semánticas, por apariencia, constitucionales, teniendo como referencia la constitución en una versión también, textual, semántica o simplista y viceversa. Dependerá del "intérprete", para considerar con seriedad e importancia si la calificación de una norma sobre su constitucionalidad adquiere prestancia y trascendencia o no y los jueces, debo entender, están calificados para hacer ese ejercicio complejo de cuestionar la constitucionalidad de una norma cuando así consideren y fundamenten. Evidentemente lo trascendental del tema no radica en la comparación normativa, sino en la actividad mental que tiene que realizar un ciudadano para concluir si es constitucional o no la norma; entonces hay una diferencia marcada entre lo obvio, lo evidente y aquello que requiere ser analizado y decidir si es o no inconstitucional y según los criterios antes indicados lo evidentemente incompatible, resulta discutible en materia de control de constitucionalidad de normas legales, de ahí la intrascendencia del criterio, porque en materia normativa nada es evidentemente inconstitucional ni evidentemente constitucional, siempre se requerirá un análisis mesurado, ponderado y con elementales criterios informativos y que necesariamente debe contar el intérprete, de este modo lo evidentemente incompatible es indeterminado, indefinido, abstracto, inconsistente y por tanto impracticable.

Tenemos que concluir que no podría cuestionarse a un juez cuando inaplica una ley por no haberlo hecho cuando la norma resulte "evidentemente incompatible" pues la argumentación por su contundencia, por su solidez, por su racionabilidad y por su profundo conocimiento de la materia puede concluir sobre la inconstitucionalidad de una norma que literalmente dice casi lo mismo que la Constitución pero que una sutil diferencia origina ese cuestionamiento de constitucionalidad, que en opinión del juez que aplica dicha norma es evidente, tanto así que lo explica con soltura, con trascendencia, con solidez y descubre ante los demás eso que no es evidente pero que está escondido en un manto de constitucionalidad y sobre todo resuelve de manera ideal el caso concreto en torno del cual se ha analizado la constitucionalidad de la norma con rango de ley.

Debemos reforzar esta idea, afirmando que las normas nunca o rara vez, son "evidentemente incompatibles" con la Constitución, pues normalmente no serianpromulgadas, entonces, establecerestacondiciónnormativa paradeclarar 
Iván Sequeiros Vargas - Ejercicio de control de constitucionalidad

por los jueces peruanos

su inaplicación es virtualmente inviable, ya que las inconstitucionalidades normalmente son sutiles, subrepticias, escondidas, disfrazadas, camufladas, por tanto, requieren debida agudeza del juez para preferir la aplicación de la Constitución en vez de la norma que la contraviene, lo que requiere lógicamente un ejercicio interpretativo cuidadoso y bastante profesional.

Si el juez estuviera limitado solamente a destapar lo que resulta manifiesto, contrario sensu, tendría que dejar pasar lo que no es evidente ni manifiesto y limitarse a aplicar la ley aun sabiendo que dicha norma no es constitucional, pero como no es evidente, hacer la "vista gorda" y permitir que se incurra en una injusticia con esa aplicación normativa, claro que no, es su obligación hacer evidente aquello que no lo es o no lo parece, solo de esa manera está ejerciendo plenamente su potestad de control de constitucionalidad.

Probablemente este sea uno de los factores que influyen en la escasa ejecutoria de control que ejercen los jueces y es necesario vencer estas reticencias y hacer justicia aplicando la Constitución, contribuye ello a la respetabilidad de la función judicial del Estado y revalora una potestad trascendental en la actividad judicial que no solo contribuye en el buen ejercicio de la función jurisdiccional propiamente dicha, sino en el racional equilibrio de las funciones del poder.

Reforzamos este criterio con evidencia incuestionable, puesto que si la norma legal fuera "evidentemente incompatible" con la Constitución, los criterios judiciales tendrían que ser los mismos, pues lo evidente no es solo para uno, sino para todos, entonces, podría resultar inclusive innecesaria la consulta a la que se refiere el artículo $14^{\circ}$ de la $\mathrm{LOPJ}^{15}$ para revisar y evaluar si la inaplicación resuelta por un juez es correcta o no, lo que indudablemente se plantea precisamente en razón del margen de debate que puede originar dicha decisión, por su naturaleza, su trascendencia y su complejidad, de manera tal que, reiteramos, ninguna norma resulta evidentemente no constitucional o viceversa a la vista del buen evaluador.

Para mayor solidez, tenemos que indicar que el mismo TC ha dejado abierta la posibilidad para que una norma discutida en su constitucionalidad ante el TC y declarada constitucional por este órgano máximo de control constitucional, puede ser inaplicado por un juez en un caso específico ${ }^{16}$, lo que nos remite a considerar que esta norma siendo evidentemente constitucional en abstracto, por que así lo ha considerado el TC puede ser sometido a análisis en torno al caso concreto y pueda ser inaplicado por un juez en torno de un caso específico, puesto que la norma declarada constitucional, no tiene carácter 
"más" constitucional que el resto de las normas, esto es, su constitucionalidad no ha sido reforzada, sino que sencillamente tiene la misma trascendencia que cualquier otra norma que viene premunido de la presunción de constitucionalidad y por tanto el margen de discusión de su constitucionalidad se mantiene incólume y por tanto discutible planteado en el caso concreto ${ }^{17}$. Se puede derivar de esta evaluación que para inaplicar una norma en las condiciones descritas el juez no tiene evidencia de la incompatibilidad de la norma, por el contrario, tendría evidencia de compatibilidad, pero aun así puede discutir esa "evidencia" y opinar lo contrario, no estando prohibido igualmente de discutir la constitucionalidad de una norma que no resulta "evidentemente incompatible" con la Constitución, es una cuestión meramente relativa, sujeta a control y decisión en función de la atribución constitucional que tiene la función judicial ${ }^{18}$.

Decir que solo puede inaplicar cuando hay evidente incompatibilidad, en suma no significa nada, no constituye limitación ninguna a la potestad de control del juez, en realidad es un concepto y contexto incierto, inviable y absolutamente subjetivo que no delimita ni sirve de referencia para que el juez efectúe el control que le atribuye la Constitución y la ley ${ }^{19}$.

Por otro lado, ¿resulta válido que el TC, en el conocimiento de un caso de su competencia ${ }^{20}$, disminuya o restrinja las atribuciones que la Constitución otorga?, literalmente sí, pero teórica y racionalmente no, veamos el por qué. El texto constitucional reiterativo es claro: “Juez si encuentras incompatibilidad entre la norma y la Constitución, aplica la Constitución", ese es el criterio básico, de ahí se deriva que al no aplicar la ley, está controlando la constitucionalidad de dicha norma, es una atribución y potestad que tiene la tendencia de favorecer la vigencia de la supremacía constitucional, propicia que los jueces no permitan vulneraciones a los derechos constitucionales y por cierto con mayor razón, que ellos no violen ningún derecho fundamental, entonces esa tendencia puede ser restringida y disponerse que el juez solo haga este ejercicio funcional cuando la incompatibilidad es evidente, creemos que no, tiene que hacerlo cuando las circunstancias del caso así lo requieren, siempre estando de por medio una cuestión de constitucionalidad, entonces la atribución de control judicial que señala el Código Político no puede ser violentado por un órgano constituido limitando esa atribución al mínimo inservible de manera tal que resulte virtualmente impracticable, inútil.

Es verdad que los derechos y las atribuciones no son absolutos, pero los límites que se establece tienen que ser de tal calidad que no impida el ejercicio de la atribución y en este caso, al indicar que la inaplicación solo será cuando 
Iván Sequeiros Vargas - Ejercicio de control de constitucionalidad

por los jueces peruanos

haya "evidente incompatibilidad" se pretende cercenar la atribución de control de los jueces y aparentemente habría surtido efecto esa disminución casi nulificante de una esencial función jurisdiccional, al extremo de hacerla estéril, pues la inactividad en materia de control por parte de los jueces no solo se debe a su falta de tiempo y retractación voluntaria, sino también a limitaciones de este orden que hacen difícil el cumplimiento de esta obligación judicial, dispuesta por la Constitución.

¿Cuál es, finalmente, la importancia de ejercer debidamente esta atribución y por qué tratamos de aclarar los márgenes dentro de los cuales se debe asumir esta prerrogativa? Indicamos anteriormente que el control de constitucionalidad, tiene el propósito último de la prevalencia de la supremacía de la Constitución, que resulta fundamental para el mantenimiento del Estado de derecho y la vigencia plena del constitucionalismo, por tanto, es de singular importancia que los jueces en el ejercicio de su atribución contribuyan a este propósito. Por otro lado, constituye un eficaz mecanismo de equilibrar las funciones del poder estatal, en la medida que contribuye a poner coto a normas legales que contravienen a la Constitución y que al ser aplicados en casos concretos, se hacen evidentes esas incompatibilidades normativas, entonces sirve de advertencia para frenar algunas tendencias excesivas (por encima de la Constitución) en el ejercicio del poder.

También contribuye a hacer plenamente vigente el texto constitucional y encontrar solución a muchos conflictos que no tienen tratamiento específico en las normas legales, estas soluciones resultan acordes con elementales principios que necesariamente están contenidos en la norma fundamental, facilitando de esta manera un ejercicio judicial mas ecuánime y ceñido a condiciones trascendentales de convivencia social que es lo que finalmente previene la Constitución.

Adicionalmente solventa la ejecutoria de los jueces debido a que la argumentación para el caso, desde la perspectiva constitucional siempre trasciende a la argumentación legal, es de mayor jerarquía y otorga mayor amplitud al juzgador para resolver el caso, lo que permite decisiones mas ecuánimes y los efectos son socialmente mejor asimilados, además que contribuyen en la conciencia constitucional.

Por último, utilizar la Constitución por los jueces, constituye un ejercicio necesario que amplia los extremos de la administración de justicia y excluye errores normativos que en ocasiones conducen a "injusticias legales" que contravienen manifiestamente con la labor trascendental del juez. 
Iván Sequeiros Vargas - Ejercicio de control de constitucionalidad

por los jueces peruanos

Debe quedar claro y definido que no estamos propiciando abuso de la potestad de control, pues ese extremo puede resultar igual o más pernicioso que no utilizar esa función, debido a que puede derivar en arbitrariedades judiciales y el efecto mas perjudicial es que el sistema normativo del Estado se tornaría inestable y extremadamente inseguro, entonces lo racional es que el uso de esta atribución sea cuando las circunstancias, el caso, y el criterio bien fundamentado lo justifican, pues tampoco se trata de ir utilizando la Constitución cuando no es necesario, en desmedro de la aplicación de normas legales que perfectamente solucionan el conflicto sin colisión constitucional alguna, en esa ponderación y mesura radica el buen uso de esta potestad y la solvencia del mismo, ya que puede ocurrir lo que regularmente ocurre con el uso desmesurado e irracional de cualquier institución, que de tanto ser mencionada pierde su importancia y propósitos, en este caso debemos ser especialmente cuidadosos y cautos en precisar que la inaplicación normativa, debe apuntar a solucionar el caso en justicia y descubrir un manifiesto despropósito normativo desde la aplicación concreta, frente a la voluntad constitucional, que no solo está contenida en la textura de la norma, sino en la exposición de motivos, en el carácter sistemático del código integrado, en la tradición, la historia constitucional, la ponderación de derechos, la necesidad de fortalecer los criterios constitucionales ya esclarecidos y sobre todo vigilar el buen y natural sentido de la Constitución que siempre apunta al desarrollo integral del Estado y el bienestar común.

No es bueno caer en la inactividad en materia de control como ha sido manifestado por la Suprema Corte de la República, por ejemplo, cuando elude dicha función, ceñido a la literalidad "absurda" del artículo $14^{\circ}$ de la LOPJ ${ }^{21}$ que utiliza el termino "sentencias" en vez de "resoluciones" y que cuando se trata de inaplicación en un "auto" no debe ser materia de consulta y por tanto materia de evaluación, pero tampoco es bueno ir al otro extremo que es un activismo innecesario en materia de inaplicación normativa; resulta idóneo solucionar el caso aplicando la Constitución y también la norma porque probablemente hay compatibilidad, pero excepcionalmente descubriremos alguna incompatibilidad que también es obligación mencionarla, aun cuando no haya evidente incompatibilidad.

\footnotetext{
Todo lo que está contenido en el Código político tiene trascendencia política.

Entiéndase Tribunal Constitucional.

3 Tenemos que recordar que antes que se "inventaran" las Cortes Constitucionales (Constitución austriaca de 1920) los únicos mecanismos de control de constitucionalidad eran el "político" y el "judicial" y, excepcionalmente un control previo, que se ejercitaba por un Consejo en el caso francés. De estos mecanismos de control, el que más desarrolló y tenía real presencia, era el control judicial que se ejercía en el sistema
} 
norteamericano (judicial review), con creciente éxito pero que en otros países no había adquirido la misma trascendencia, por el contrario, al parecer el sistema solo funcionaba para los norteamericanos, como ocurre hasta la actualidad.

4 Durante la corta vigencia de la Constitución de 1979 (doce años) y el documento del año 1993 - como lo llama Borea Odría - (15 años), la información documentada que se tiene abarca tres casos.

5 Inaplicable el artículo $51^{\circ}$ del Código Penal (concurso real retrospectivo). Consulta $N^{\circ} 3166-2002$ y Consulta No 3476-2002.

6 Solo para dar una idea, el proceso penal sumario es un despropósito constitucional; el artículo $257^{\circ}$ del Código de Procedimientos Penales es inconstitucional, etc.

7 Es nula y sin efecto cualquier ley en cuanto se oponga a la Constitución. Son nulos igualmente los actos de los que usurpen funciones públicas y los empleos conferidos sin los requisitos prescritos por la Constitución y las leyes.

8 Cuando haya incompatibilidad entre una disposición constitucional y una legal, se preferirá la primera.

9 Es preciso informar que el texto inicial de dicha norma solo pretendía la opción de plantear la cuestión de inconstitucionalidad ante el TC por parte del juez que encuentre incompatibilidad entre una norma y la Constitución.

10 Teoría de separación de poderes (artículo $43^{\circ}$ último párrafo)

11 Se ha normativizado este concepto en la segunda disposición final de la Ley Orgánica del TC que señala que la inaplicación de las normas por parte de los jueces, solo es viable, cuando por vía interpretativa es imposible una adecuación de la norma al orden constitucional.

12 Casos números: 145-99-AA/TC; 1109-2002-AA/TC; 410-2002-AA/TC, entre otros.

${ }^{13}$ Los jueces y tribunales solo inaplican disposiciones que estimen incompatibles con la Constitución cuando por vía interpretativa no sea posible la adecuación de tales normas al ordenamiento constitucional, segunda disposición final de la Ley Orgánica del Tribunal Constitucional.

14 Buscamos explicaciones prácticas que nos aclaren el panorama. Artículo 26º Principios que regulan la relación laboral:

En la relación laboral se respetan los siguientes principios:

Igualdad de oportunidades sin discriminación. Las normas militares y policiales dicen que para ingresar a dichas fuerzas se requiere medir más de un metro setenta. Comparando las normas podemos concluir fácilmente que hay incompatibilidad evidente, pues cómo una norma puede preferir solo a los que tienen determinada estatura, cuando la Constitución dice que no se debe discriminar. Cualquier persona racionalmente explicará y fundamentará el por qué dicha norma puede no ser incompatible con la Constitución, pero una mera comparación bajo el rubro de la incompatibilidad resulta más que evidente, entonces llegamos al mismo punto, afirmar si una norma es o no incompatible requiere necesariamente un ejercicio mental complejo que en nuestros términos se denomina interpretación, que es la única forma de establecer si una norma es o no constitucional.

15 Debemos destacar que el propósito de la consulta en esta materia, al igual que la consulta cuando se declara fundada una acción popular, aun cuando no se haya impugnado, tiene el especial énfasis de destacar que no se trata solo de una actividad jurisdiccional, sino que trasciende esa función e ingresa en el complejo ámbito de evaluar si las normas (en esencia decisiones de quienes detentan márgenes de poder importantes en el Estado) son válidas o no desde la perspectiva constitucional y el pronunciamiento de la máxima instancia del Poder Judicial, precisamente otorgará solvencia a esa apreciación, indicando que ya no es la opinión de un juez o una sala en el caso concreto y que se han enterado además del juez, las partes, sino de un acto judicial de ejercicio de poder de gobierno a través del control de una norma legal, o visto al revés, a través de la prevalencia de la Constitución. Allí radica la importancia de la consulta.

16 Acción de inconstitucionalidad contra la Ley $\mathrm{N}^{\circ}$ 25202, Ley de la Bolsa de Trabajo, de fecha 13 de agosto de 1990, interpuesta por el Ministerio Público, el mismo que fue declarado constitucional.

17 La demanda de amparo presentada por CAPECO casi simultáneamente a la inconstitucionalidad de la norma, pedía la inaplicación de la citada Ley N²5202. La Corte Superior de Lima, en marzo de 1991, declaró inaplicable la citada norma legal bajo el argumento que dicha norma es inconstitucional.

18 Admito que el asunto tiene varias vertientes y el debate es rico y muy interesante; para mayor ilustración revisar "relaciones entre el Tribunal Constitucional y el Poder Judicial, artículo publicado en la revista Gaceta del Tribunal Constitucional. N². Abril-junio. Lima: Gaceta Jurídica, 2006.

19 Revisar a Carpio Marcos, Edgar. Control difuso e interpretación constitucional. Módulo 4 del curso de formación Código Procesal Constitucional - Academia de la Magistratura. Lima, 2004.

${ }_{20}$ Control de constitucionalidad abstracto en base a una acción de inconstitucionalidad.

${ }^{21}$ El citado artículo tiene tres partes, en el primer párrafo se indica "[...] de conformidad con el artículo $236^{\circ}$ (se refiere a la Constitución de 1979), cuando los magistrados al momento de fallar el fondo de la cuestión 
Iván Sequeiros Vargas - Ejercicio de control de constitucionalidad

por los jueces peruanos

de su competencia, en cualquier clase de proceso o especialidad, encuentren que hay incompatibilidad entre su interpretación de una disposición constitucional y una con rango de ley, resuelve la causa con arreglo a la primera". Destacamos fallar el fondo de la cuestión, no se refiere necesariamente a sentencias, sino a resolver el fondo bajo cualquier forma resolutiva. Y la segunda parte de la norma dice: "[...] las sentencias así expedidas son elevadas en consulta a la Sala Constitucional y Social de la Corte Suprema, si no fueran impugnadas. Lo son igualmente las sentencias de segunda instancia en las que se aplique el mismo precepto, aun cuando contra estas no quepa recurso de casación". De esta literalidad "sentencia" es que se basó la Suprema Corte para no evaluar la inaplicación normativa, porque la consulta se trataba de un "auto". Esta manera de evaluar no toma en cuenta la importancia del rol judicial en el control de constitucionalidad, debido a que reduce esta actividad a una intrascendencia espantosa, al no percatarse que inaplicar una norma por colisión con la Constitución no tiene que ver con sentencias o no sentencias, sino que va mucho mas allá, se trata, conforme queda claro, de evaluar si los órganos legislativos, han expedido una norma con rango de ley, dentro del marco constitucional o no y la consulta a la Suprema Corte tiene la importancia de convalidar esa decisión judicial (o descartarla) a fin de advertir al órgano legislativo que en opinión ya no solo del juez, sino del Poder Judicial, hay una norma que resulta incompatible con la Constitución, de esta manera se propicia todos los fines que tiene el trascendental asunto del control de constitucionalidad. 